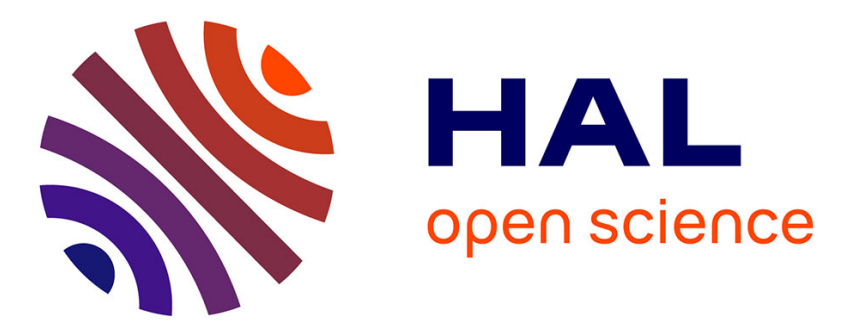

\title{
Do activating legacy concerns make farmers more likely to support conservation programmes?
}

Gilles Grolleau, Naoufel Mzoughi, Claude Napoleone, Claire Pellegrin

\section{To cite this version:}

Gilles Grolleau, Naoufel Mzoughi, Claude Napoleone, Claire Pellegrin. Do activating legacy concerns make farmers more likely to support conservation programmes?. Journal of Environmental Economics and Policy, 2020, 10 (2), pp.115-129. 10.1080/21606544.2020.1807410 . hal-02918364

\section{HAL Id: hal-02918364 \\ https://hal.inrae.fr/hal-02918364}

Submitted on 20 Aug 2020

HAL is a multi-disciplinary open access archive for the deposit and dissemination of scientific research documents, whether they are published or not. The documents may come from teaching and research institutions in France or abroad, or from public or private research centers.
L'archive ouverte pluridisciplinaire HAL, est destinée au dépôt et à la diffusion de documents scientifiques de niveau recherche, publiés ou non, émanant des établissements d'enseignement et de recherche français ou étrangers, des laboratoires publics ou privés.

\section{(c)(1)}

Distributed under a Creative Commons Attribution| 4.0 International License 


\title{
Do activating legacy concerns make farmers more likely to support conservation programmes?
}

\author{
Gilles Grolleau , Naoufel Mzoughi , Claude Napoléone \& Claire Pellegrin
}

To cite this article: Gilles Grolleau , Naoufel Mzoughi , Claude Napoléone \& Claire Pellegrin (2020): Do activating legacy concerns make farmers more likely to support conservation programmes?, Journal of Environmental Economics and Policy, DOI: $10.1080 / 21606544.2020 .1807410$

To link to this article: https://doi.org/10.1080/21606544.2020.1807410

曲 Published online: 19 Aug 2020.

Submit your article to this journal $₫$

Q View related articles $\sqsubset$

View Crossmark data 


\title{
Do activating legacy concerns make farmers more likely to support conservation programmes?
}

\author{
Gilles Grolleau $\left(^{a}{ }^{a}\right.$, Naoufel Mzoughi $\oplus^{b}$, Claude Napoléone ${ }^{b}$ and Claire Pellegrin ${ }^{b}$ \\ ${ }^{a}$ CEREN EA 7477, Burgundy School of Business, Univ. Bourgogne Franche-Comté, Dijon, France; ${ }^{b}$ Ecodeveloppement, \\ INRAE, Avignon, France
}

\begin{abstract}
Recent findings in behavioural sciences suggest that individuals may engage more in pro-social behaviour if they are prompted to reflect on how they will be remembered. Using experimental survey data with a between-subjects design, we examine the relevance of activating legacy concerns in the context of small businesses. More precisely, we investigate farmers' intention to participate in conservation programmes for the sake of legacy. While the legacy effect is not found to be stronger than another priming manipulation at the global level, it is significant among first-generation farmers as opposed to multigeneration farmers. Inherited family farms are more prone to be influenced by non-environmental legacies whereas first-generation farmers can be more interested in leaving an environmental legacy.
\end{abstract}

ARTICLE HISTORY

Received 25 May 2020

Accepted 5 August 2020

\section{KEYWORDS}

Conservation programmes; experiment; family business; first- and multi-generation farmers; legacy

\section{JEL NUMBERS}

Q19; Q57; D9

\section{Introduction}

Conservation efforts are frequently perceived by contemporary individuals as requiring a sacrifice of immediate gratification in order to preserve benefits that will be enjoyed by future generations (Vandenbergh and Raimi 2015). Moreover, some findings in behavioural sciences suggest that individuals may behave pro-socially for the sake of their legacy (Wade-Benzoni, Sondak, and Galinsky 2010, 2012; Zaval, Markowitz, and Weber 2015; Vandenbergh and Raimi 2015). According to the previous authors, when individuals are asked to think about how they will be remembered, they are more prone to make pro-environmental efforts, compared to a situation where they are not primed with a legacy motive.

Based on the previous findings, we examine in this paper whether activating legacy concerns among farmers can be leveraged to encourage more positive attitudes regarding environmental measures. In many countries, including France, farms dominate largely the agricultural landscape. Farmers are frequently described as being stewards of the environment and are frequently solicited by society to protect it for the well-being of the current and future generations. Several policies, notably based on a traditional cost-benefit analysis, encourage farmers to participate in conservation programmes and maintain their commitment, but the results fall short of expectations and remain a hot issue in many countries (Vercammen 2011; Lastra-Bravo et al. 2015; Liu, Bruins, and Heberling 2018). If activating legacy concerns is effective to enhance attitudes regarding environmental efforts, the aggregated effect can be considerable. The legacy lever could constitute a low-cost nudge to promote greener farming, which seems very relevant in the current context of economic downturn with likely budgetary restrictions.

Using an experimental survey - i.e. where respondents are randomly assigned to alternative versions (Gaines, Kuklinski, and Quirk 2007) - among a sample of French farmers, we test the 
hypothesis that priming farmers with a legacy motive can increase their intention to participate in (and commitment to) an environmental conservation programme. As far as we know, very few studies, especially using an experimental design, prompt legacy issues (Wade-Benzoni et al. 2012; Zaval, Markowitz, and Weber 2015). Our study aims at investigating whether the appeal of leaving a positive and lasting legacy makes sense for farmers and could enrich the policy toolbox. Indeed, most previous studies used either students or Amazon Mechanical Turk (https://www.mturk.com/ ) workers in domains unrelated to their professional life or to the organizations they manage. Unlike the previous studies, we investigate the effect of a legacy manipulation among professionals in a domain related to their organization and main activity, i.e. farming. Moreover, while previous literature (e.g. Zaval, Markowitz, and Weber 2015) examined the effect of legacy compared to a control treatment without priming, we use three treatments: a control treatment, a legacy priming one and a non-legacy priming one.

We also investigate whether first-generation farmers exhibit different patterns compared to multigeneration ones. Nevertheless, we do not make a definitive hypothesis regarding which category will be more concerned about its own legacy, although conceivably legacy issues may seem more salient to multi-generation farmers than to someone who is a first-generation farmer because the former has seen firsthand how earlier farmers are remembered (Wade-Benzoni 2016). This insight is consistent with the definition of legacy as 'something transmitted by or received from an ancestor or predecessor or from the past' (https://www.merriam-webster.com/dictionary/legacy). In our analysis, legacy corresponds notably to how one will be remembered by others, and for what values and achievements.

The remainder of the paper is as follows. The next section is devoted to a literature overview about participation in conservation programmes and other agro-environmental schemes and the logic behind our focus on legacy concerns. Section 3 is devoted to methods and data. In Section 4, the main results are presented and discussed. Section 5 concludes and provides implications.

\section{Participation in conservation programmes: from conventional drivers to legacy considerations}

A huge literature is devoted to the factors influencing farmers' attitudes and behaviour regarding environmental schemes and reviewing it is beyond the scope of our paper. Interestingly, while the examined factors frequently included farm(ers)' characteristics and contextual influences (e.g. DeFrancesco et al. 2008), several syntheses stress that it is very difficult to draw consistent patterns. For instance, Siebert, Toogood, and Knierim (2006) summarize a sizeable literature on factors affecting European farmers' participation in biodiversity policies and emphasize that the 'support for practices oriented towards biodiversity protection should not be viewed in a static sense - as a situation determined by one or several influencing factors - but, rather, as a process marked by interaction'. They also stress that financial compensation and incentives are necessary, though not enough to guarantee farmers' participations. Similarly, in a highly-cited paper, Knowler and Bradshaw (2007) recognize the role of financial incentives but argue that the primary finding of their synthesis is that there are few if any universal variables that regularly explain the adoption of conservation agriculture across past analyses.

To our knowledge, no legacy-related study has been conducted among farmers. Nonetheless, most people and especially entrepreneurs are interested in leaving a positive legacy, which can offer symbolic immortality, effectively extending the self beyond the limits of one's lifespan (Fox, Tost, and Wade-Benzoni 2010). Legacy building, especially in farming and business contexts can take the form of working to ensure the long-term viability and success of the organization and leaving it stronger, more productive, more laudable, and more valuable than it was before (Wade-Benzoni 2016). Legacy nudges such as legacy registries, exploit the inherent desire of people to transcend death and leave something behind that will connect them to future generations (Vandenbergh and Raimi 2015). 
As mentioned in the introduction, we make a special focus in our study to the potential differentiated effect of activating legacy concerns between first- and multi-generations farmers. Multi-generation farmers fit relatively well the definition of a family business, especially in the dimension related to succession (Chua, Chrisman, and Sharma 1999; Chrisman, Chua, and Sharma 1998). First-generation farmers also fit this definition, but are not in the same development stage. Interestingly, Chua, Chrisman, and Sharma (1999) propose to define a family business as

a business governed and/or managed with the intention to shape and pursue the vision of the business held by a dominant coalition controlled by members of the same family or a small number of families in a manner that is potentially sustainable across generations of the family or families.

According to Inwood (2013) each group (first-generation [FG] or multi-generation [MG])

embodies a distinct set of economic and non-economic values that underlay the strategies FG and MG farmers use to structure their farm operations. Differences in goals can have nuanced, but profound, effects on the socialization of future heirs to farm life and the investments made to accommodate the next generation.

This dimension of our study also echoes the literature on entrepreneurial legacies and transgenerational entrepreneurship (Jaskiewicz, Combs, and Rau 2015; see also Barbera, Stamm, and DeWitt 2018). The preceding authors argued that the presence of entrepreneurial legacies will motivate and give meaning to current and future entrepreneurship decisions. In the case of multi-generation farmers, the entrepreneurial legacies or 'the family's rhetorical reconstruction of past entrepreneurial achievements or resilience' (Jaskiewicz, Combs, and Rau 2015, 29) are less likely to be directly related to environmental considerations. Indeed, even if the label is misleading, the legacies of these family farms are more likely to be associated with the Green Revolution, characterized by intensive farming and productivity increases at the expense of the environment (Borlu and Glenna 2020). These legacies will influence the farmers' mindsets and achievements in general and more specifically in relation to the natural environment.

Moreover, we contend that multi-generation farmers are strongly influenced by the identity and legacy left by previous generations (e.g. increasing the farm size, managing a productivist farm or maintaining a renowned vineyard), while first-generation farmers may be more susceptible to the idea of establishing a possible legacy based on environmental achievements (see Bang, Zhou Koval, and Wade-Benzoni 2017; see also Lequin, Grolleau, and Mzoughi 2019). Indeed, on farms that have been handed down from father to son for several generations, the legacy of these farmers is more likely to be related to non-environmental issues, especially from the viewpoint of the family and community. Conversely, first-generation farmers are more likely to be environmentally conscious and interested in environmental issues, either because of their personal values, education or an influential social context. For instance, Dewey (2017) reports that (i) the increasing number of young Americans who are leaving desk jobs for farming did not grow up in agricultural families, and (ii) the majority of these young farmers are 'far likely than the general farming population to grow organically, limit pesticide and fertilizer use, diversify their crops or animals, and be deeply involved in their local food systems'. Interestingly, there was also a noticeable trend in Zaval, Markowitz, and Weber's (2015, Supplementary material) data indicating that the legacy prime is more effective at increasing donations among young, non-parent participants compared to parents.

In a similar vein, perhaps the first-generation farmers in our sample have not yet thought much about their personal legacy before being asked to do so in our study. Indeed, first-generation farmers do not already have a concrete and non-environmental existing legacy related to farms, unlike multigeneration farmers. Consequently, it is possible that legacy may mean something different to firstgeneration farmers due to their more pronounced environmental concerns. Moreover, this line of reasoning is consistent with recent research on 20 European countries, suggesting that new entrants into agriculture are more entrepreneurially oriented than established ones (Pintado and Sánchez 2017). This stronger entrepreneurial orientation notably corresponds to higher levels of risk-taking, proactiveness and innovativeness. These qualities are frequently needed to consider and adopt 
environmentally-friendly innovations, which can be less productive (from a yield viewpoint) and riskier in some contexts, but not necessarily less profitable compared to conventional practices.

\section{Method}

In June 2017, we surveyed by mail 4423 individuals, corresponding to the whole farmer population in the Vaucluse area (Southern France). In order to test the legacy motive, we used an experimental survey with a between-subjects design. Our survey is composed of two main parts that are presented to respondents in a chronological order (see Table 1).

After reading introductory instructions, farmers are either not primed at all or exposed to a nonlegacy prime or to a legacy prime. Using this prime does not preclude that farmers have or not preexisting legacy concerns. The objective of this prime is to activate legacy concerns at the time of administration. Moreover, even if farmers have preexisting legacy preferences, there is no reason to believe that their distribution is unequal across treatments, given that each participant was randomly assigned to one of the three treatments. In the control treatment (T1 - no question), farmers were not primed neither with a legacy motive, nor with another prime. In the treatment 2 (T2 - nonlegacy question), we implemented a 'neutral' prime, to distinguish the possible effect of prime per se from the effect of the activation of legacy concerns. Farmers were invited to describe in three words their soils' quality. The main criterion for choosing this question was related to the realism of the scenario and to avoid a too artificial item. One may argue, however, that T2 can also be considered as an environmental prime, but that this reasoning seems unlikely. Indeed, $70 \%$ of the words reported by farmers were related to technical properties of soils (presence or not of stone, limestone, clay and loam, siliceous or not, sandy or not, hard vs. light, aridity ...) and only $12 \%$ to the environment (use or not of pesticides, natural, biodiversity, healthy, preserved ...). In the treatment 3 (T3 priming a legacy motive), farmers were invited to describe in three words how they want to be remembered by next generations. In T3, most words that respondents mentioned are either related to the environment (about 43\%) or to individual qualities (e.g. being courageous or honest), notably related to the farming profession (about 37\%). The same kind of inducing legacy motives has been tested by Zaval, Markowitz, and Weber (2015) who found convincing support of its capacity to enhance legacy concerns.

Then, all farmers were invited to read an identical hypothetical scenario inspired by the ecological mitigation policy in France, in which the state legally requires from developers to avoid, reduce and mitigate environmental damages as much as possible. Regarding the use of hypothetical scenarios or questions, Thaler (1987) argues that it is not only convenient, but also fast and inexpensive. Although we did not reward participants, we concur with several authors arguing that such experimental surveys can provide reliable evidence, notably from a qualitative viewpoint (Camerer and Hogarth 1999; Rubinstein 2001; Read 2005; Thaler 2015). To make justice to this issue and avoid a biased perspective, we admit that hypothetical questions can also raise legitimate concerns such as facilitating a social desirability bias and not eliciting exact preferences, notably because of the hypothetical bias (e.g. Charness, Gneezy, and Imas 2013; Hertwig and Ortmann 2001). It is noteworthy that farmers

Table 1. Experiment design and summary of the three treatments.

\section{Introductory instructions}

(Treatment 1) No prime (Treatment 2) Non-legacy prime 'How would you describe, in three words, the quality of soils in your farm?'

Hypothetical scenario about compensating a loss of biodiversity Willingness to participate Willingness to participate Commitment period Commitment period Information about the farm and the farmer
(Treatment 3) Legacy prime 'How would you like to be remembered, as a farmer, by next generations, in three words?'

Willingness to participate Commitment period 
may be involved in ecological mitigation policy, but their involvement is not the only option and depends on several factors such the specific location, considered project and institutional environment. While there is no valuable synthesis on the involvement of farmers in ecological mitigation policy, there is a sufficient similarity between farmers' role in agri-environmental policy and Payments for Environmental Services (PES) for using this accumulated knowledge on PES to build academic scenarios on ecological mitigation measures (see an example in Calvet et al. 2019).

Hence, as a result of a hypothetical building infrastructure that caused ecological damages, surveyed farmers were invited to mitigate this environmental loss by establishing ecological corridors on their farms and receiving in turn a monetary reward (300€/year/ha devoted to the considered programme). This financial reward is equivalent to the mean amount of subsidies for a similar type of measures in the French PES policy: the Agri-Environmental and Climatic Measures (MAEC - a voluntary enrollment for five years of farmers who select desired measures among a given set). ${ }^{1}$ Ecological corridors are issued from the environmental policy called 'Trame Verte et bleue' (green and blue network) which is managed by the Environment Ministry. ${ }^{2}$ Interestingly, the PES/MAEC subsidies may be used for farmers who enroll in this policy. All participants were invited to mention their willingness to participate in this programme using a Likert scale from 1 (Not at all) to 10 (Definitely). We also invited them to indicate a commitment period up to 15 years or more by 1year increment. Noteworthy, for participants in the control treatment (not primed), the survey started directly by the questions devoted to the environmental attitude.

In sum, in order to investigate a possible effect of activating legacy concerns, a group of participants was exposed to the treatment variable. The collected data is then compared to the data from the control group, which was not exposed to the treatment variable. This experimental strategy allows us to detect whether the independent variable has any causal impact on the behavioural intentions of the participants. A pre-test of the survey instrument has been achieved among some experts and a sample of 9 farmers not included in the end-survey. When we designed the survey instrument, we looked for agro-environmental measures that were likely to be proposed to farmers in the near future. We also looked for similar measures that were under consideration in similar close regions, notably to determine a realistic level of compensation. Given our efforts to design a realistic scenario ex ante and the feedback of experts and farmers on the end-version of the survey instrument, we believe that the used scenario was appropriate. Moreover, no surveyed farmer questioned ex post the realism of the scenario. Moreover, the scenario was considered as highly realistic, notably because of the expected urban growth in Vaucluse (Arrighi and Samyn 2016). This growth should lead to a need of ecological mitigation that could be achieved by local farmers who occupy $85 \%$ of the whole area.

Three hundred twenty seven farmers answered the questionnaire (7.39\% of surveyed farmers). Although it is relatively low, the response rate is adequate given that, due to unexpected postal delay, many farmers (notably, among cereals producers) received the survey during a busy period, especially because of the (hay) harvest. Moreover, previous studies reported that French farmers are more reluctant to reply to surveys compared to other countries (e.g. Mzoughi 2014). We concur that getting a higher share of farmers could have improved the quality of results. Nevertheless, the difficulty of surveying French farms and firms is well-known and our response rate is somewhat similar to the rates found in several studies on French firms or farms. For instance, based on a cross-national mail survey in 22 countries, Harzing (2000) reports that response rates in France are among the lowest. In addition, Henriques et al. (2004) who investigated environmental practices in several OECD countries found response rates ranging from $9.3 \%$ in France to $34.7 \%$ in Norway. Interestingly, a low response rate does not necessarily affect the internal validity of the study but can affect the generalizability of study to the whole farming population, even if some recent research points out that this outcome is far from being systematic (Mullinix et al. 2015).

Some descriptive statistics for the whole sample and by treatment are reported in Table 2. Individuals' characteristics are not significantly different across treatments, except for the proportions of fruit-growers and vegetables producers which are relatively higher in treatments T3 (legacy prime) 
Table 2. Sample summary statistics.

\begin{tabular}{|c|c|c|c|c|c|c|c|c|c|c|}
\hline & \multirow[b]{2}{*}{ Variables } & \multicolumn{2}{|c|}{$\begin{array}{l}\text { Whole sample } \\
\qquad(N=327)\end{array}$} & \multicolumn{2}{|c|}{$\begin{array}{c}\text { Treatment } T 1, \\
\text { no prime }(N= \\
111)\end{array}$} & \multicolumn{2}{|c|}{$\begin{array}{c}\text { Treatment } T 2, \\
\text { non-legacy } \\
\text { prime }(N= \\
101)\end{array}$} & \multicolumn{2}{|c|}{$\begin{array}{c}\text { Treatment T3, } \\
\text { legacy prime } \\
(N=115)\end{array}$} & \multirow[b]{2}{*}{ Kwallis test } \\
\hline & & Mean & S.D & Mean & S.D & Mean & S.D & Mean & S.D & \\
\hline \multicolumn{2}{|c|}{ Gender ( $=1$ if Male) } & 75.3 & 0.43 & 75.4 & 0.43 & 78.7 & 0.41 & 71.9 & 0.45 & ns \\
\hline \multicolumn{2}{|c|}{ Age } & 51.97 & 13.69 & 52.51 & 12.80 & 50.56 & 15.71 & 52.49 & 12.58 & ns \\
\hline \multicolumn{2}{|c|}{ Education (=1 if high educated) } & 0.48 & 0.50 & 0.49 & 0.50 & 0.47 & 0.50 & 0.47 & 0.50 & ns \\
\hline \multirow[t]{4}{*}{ Activity } & Fruit growing & 0.12 & 0.33 & 0.09 & 0.28 & 0.09 & 0.28 & 0.18 & 0.39 & ** \\
\hline & Vegetables production & 0.10 & 0.30 & 0.16 & 0.37 & 0.07 & 0.25 & 0.08 & 0.27 & $*$ \\
\hline & Viticulture & 0.54 & 0.49 & 0.54 & 0.50 & 0.58 & 0.49 & 0.51 & 0.50 & ns \\
\hline & Cereals & 0.04 & 0.21 & 0.03 & 0.18 & 0.06 & 0.23 & 0.05 & 0.22 & ns \\
\hline \multirow{2}{*}{\multicolumn{2}{|c|}{$\begin{array}{l}\text { Organic production } \\
\text { Parents (=1 if farmers) }\end{array}$}} & 0.31 & 0.46 & 0.35 & 0.48 & 0.25 & 0.43 & 0.32 & 0.47 & ns \\
\hline & & 0.67 & 0.47 & 0.61 & 0.48 & 0.69 & 0.46 & 0.7 & 0.46 & ns \\
\hline
\end{tabular}

$\left({ }^{*}\right)$ and $\left({ }^{* *}\right)$ refer to the significance of the Kruskal-Wallis test at the $10 \%$ and $5 \%$ levels, respectively. ns stands for not significant.

and T1 (no prime), respectively. Moreover, our final sample is balanced across treatments, with $34 \%$ of respondents in the treatment T1,31\% in T2, and 35\% in T3. Nevertheless, while our sample is balanced in terms of age and gender between multi- and first-generation farmers, the two subsamples are significantly different in terms of education, main activity and organic production (Table 3). Furthermore, as reported in Table 4, our sample is representative of the whole population of farmers in the Vaucluse area in terms of gender, average age, mean size of farms, and the proportions of fruit-growers and vegetables producers. However, there are relatively less viticulture and fewer cereal producers in our sample compared to the full population. The proportion of organic producers is also relatively higher in our sample compared to the whole population.

Given that the responses are not normally distributed, we use a non-parametric test to examine if there are statistically significant differences between groups of individuals. We use the Kruskal-Wallis test (Kruskal and Wallis 1952) because it is generally used when there are more than two groups and the dependent variable is continuous or ordinal, which is the case of our main variables. Moreover, given that our respondents in the three treatments have to answer two questions, i.e. about the programme support and duration of the commitment, we also correct for multiple hypotheses testing using the MHTEXP Stata module developed by List, Shaikh, and Xu (2019). This module allows us to simultaneously compare all treatments and provides an adjusted $P$-value. Interestingly, this procedure also reports the outcome of more classical ones, namely the Bonferroni and Holm corrections (see List, Shaikh, and Xu 2019 for more details about the previous correction procedures).

Then, the effect of legacy and non-legacy priming on the level of programme support is examined using an ordered probit regression (Greene 2003). More formally, assume $Y_{i}$ to be our observed

Table 3. Sample statistics by type of farmer (MG versus FG).

\begin{tabular}{|c|c|c|c|c|c|}
\hline \multirow{2}{*}{\multicolumn{2}{|c|}{ Variables }} & \multicolumn{2}{|c|}{$\begin{array}{l}\text { Multi-generation farmers } \\
\qquad(N=204)\end{array}$} & \multicolumn{2}{|c|}{$\begin{array}{l}\text { First-generation farmers } \\
\qquad(N=100)\end{array}$} \\
\hline & & Mean & S.D & Mean & S.D \\
\hline \multicolumn{2}{|c|}{ Gender ( $=1$ if Male) } & 76.9 & 0.42 & 69 & 0.46 \\
\hline \multicolumn{2}{|c|}{ Age } & 51.86 & 13.47 & 51.42 & 14.30 \\
\hline \multicolumn{2}{|c|}{ Education $(=1 \text { if high educated })^{* * *}$} & 0.40 & 0.49 & 0.62 & 0.48 \\
\hline \multirow[t]{4}{*}{ Activity } & Fruit growing & 0.14 & 0.34 & 0.10 & 0.30 \\
\hline & Vegetables production*** & 0.05 & 0.22 & 0.21 & 0.40 \\
\hline & Viticulture $^{* * *}$ & 0.59 & 0.49 & 0.43 & 0.49 \\
\hline & Cereals* & 0.07 & 0.25 & 0.02 & 0.14 \\
\hline \multicolumn{2}{|c|}{ Organic production ${ }^{* * *}$} & 0.25 & 0.43 & 0.42 & 0.49 \\
\hline
\end{tabular}

$\left({ }^{*}\right)$ and $\left({ }^{* *}\right)$ refer to the significance of the Mann-Whitney-Wilcoxon test comparing MG and FG farmers at the $10 \%$ and $1 \%$ levels, respectively. 
Table 4. Comparison between our sample and the full population of farmers in Vaucluse area.

\begin{tabular}{lcc}
\hline Characteristics & Our sample & Full population \\
\hline Proportion of male & $75 \%$ & $71 \%$ \\
Average age & 52 & 54 \\
Average size & 18.64 ha & 21 ha \\
Main activity: fruit-growing & $12 \%$ & $13 \%$ \\
Main activity: vegetables production & $10 \%$ & $9 \%$ \\
Main activity: viticulture & $54 \%$ & $59 \%^{*}$ \\
Main activity: cereals & $4 \%$ & $11 \%^{* *}$ \\
Share of organic production & $31 \%$ & $20.5 \%^{* * *}$ \\
\hline
\end{tabular}

$\left({ }^{*}\right),\left({ }^{* *}\right)$, and $\left(^{* *}\right)$ stand for significance of a $t$-test of proportions at the $10 \%, 5 \%$ and $1 \%$ levels, respectively. Information regarding the full population are available at http://www.paca.chambres-agriculture.fr/notre-agriculture/chiffres-cles/\#c48632 (for age), https://stats.agriculture.gouv.fr/cartostat/\#sly=g_dep_e_DR;sid=84;l=fr;i=empl1.partfcexcoex10;v=map7 (for gender), http:// agreste.agriculture.gouv.fr/IMG/pdf/R9318A20v2.pdf (for size and main activity), and, https://www.agencebio.org/vos-outils/ les-chiffres-cles/ (for organic production). For average age, the information is not available at the studied scale, that is, the Vaucluse area. We thus, considered its value at the regional scale, namely the PACA region.

variable - corresponding to the level of support - defined by:

$$
\left\{\begin{array}{ccc}
Y_{i}=1 \text { (no support at all) } & \text { if } & Y_{i}^{*} \leq u_{1} \\
Y_{i}=2 & \text { if } & u_{1}<Y_{i}^{*} \leq u_{2} \\
& \vdots & \\
Y_{i}=10 \text { (fully support) } & \text { if } & Y_{i}^{*}>u_{9}
\end{array}\right.
$$

$Y_{i}^{*}$ is the latent variable influencing the reported level of programme support for the $i^{\text {th }}$ individual. $u_{1}$ to $u_{9}$ correspond to the threshold parameters. We consider the following ordered probit model for the dependent variable:

$$
Y_{i}^{*}=X_{i} \beta+\varepsilon_{i}
$$

where $X_{i}$ is the vector of exogenous variables, $\beta$ represents slope coefficients to estimated, and $\varepsilon_{i}$ is the disturbance term, which is assumed to be normally distributed with zero mean.

Regarding the duration of the commitment, which is a count variable, its relationship with the (legacy and non-legacy) priming is examined using a Poisson regression (Cameron and Trivedi 1998). Let $Y_{i}(i=1,2, \ldots, N)$ be the dependent variable, which represents the number of years of commitment suggested by each individual. Assume that $Y_{i}$ is independently Poisson distributed. The conditional mean is specified as: $E\left(Y_{i} \mid X_{i}\right)=\exp \left(X_{i}^{\prime} \beta\right)$, where $X_{i}$ and $\beta$ are the vectors of explanatory variables and parameters, respectively.

\section{Results}

The distributions of responses and mean of individuals' responses by treatment are presented in Tables 5 and 6. Even if slight variations can be observed, the Kruskal-Wallis test shows that farmers did not react significantly differently to the treatments for both the level of support $(P$-value $=$ $0.3186)$ and the length of their commitment period $(P$-value $=0.3483)$. Moreover, when correcting for multiple hypotheses testing (Table 7), the results remain similar. In other words, although

Table 5. Distribution of responses and mean programme support by treatment $(N=327)$.

\begin{tabular}{lccccccccccc}
\hline & \multicolumn{10}{c}{ Percentage of responses by level } & Mean level (standard deviation) \\
\cline { 2 - 10 } Treatment & 1 & 2 & 3 & 4 & 5 & 6 & 7 & 8 & 9 & 10 & Mean (3.28) \\
\hline T1 (no question) & 23 & 3 & 3 & 3 & 18 & 7 & 8 & 10 & 7 & 18 & $6.23(3.33)$ \\
T2 (neutral question) & 17 & 5 & 6 & 2 & 9 & 5 & 11 & 14 & 3 & 28 & $6.00(3.22)$ \\
T3 (Legacy motive) & 17 & 4 & 6 & 5 & 11 & 8 & 10 & 12 & 3 & 24 & \\
\hline
\end{tabular}


Table 6. Distribution of responses and mean commitment duration by treatment $(N=327)$.

\begin{tabular}{|c|c|c|c|c|c|c|c|c|c|c|c|c|c|c|c|c|}
\hline \multirow[b]{2}{*}{ Treatment } & \multicolumn{15}{|c|}{ Number of years in percentage } & \multirow{2}{*}{$\begin{array}{c}\text { Mean duration (standard } \\
\text { deviation) }\end{array}$} \\
\hline & 0 & 3 & 4 & 5 & 6 & 7 & 8 & 9 & 10 & 11 & 12 & 13 & 14 & 15 & +16 & \\
\hline T1 (no question) & 14 & 26 & 2 & 11 & 9 & 1 & 2 & 3 & 12 & 0 & 1 & 0 & 0 & 1 & 18 & $6.76(5.35)$ \\
\hline $\begin{array}{l}\text { T2 (neutral } \\
\text { question) }\end{array}$ & 14 & 23 & 2 & 8 & 4 & 3 & 1 & 2 & 5 & 0 & 0 & 0 & 0 & 7 & 31 & $8.39(6.27)$ \\
\hline T3 (Legacy motive) & 10 & 31 & 2 & 10 & 5 & 0 & 0 & 5 & 9 & 0 & 0 & 0 & 0 & 3 & 25 & $7.50(5.80)$ \\
\hline
\end{tabular}

Table 7. Multiple hypotheses testing (simultaneous comparison of all treatments).

\begin{tabular}{|c|c|c|c|c|c|c|c|c|c|c|c|}
\hline \multicolumn{6}{|c|}{ Programme support } & \multicolumn{6}{|c|}{ Duration of the commitment } \\
\hline \multirow[b]{3}{*}{$\begin{array}{l}\text { Compared } \\
\text { treatments }\end{array}$} & \multirow{3}{*}{$\begin{array}{l}\text { Difference } \\
\text { in } \\
\text { means }\end{array}$} & \multicolumn{4}{|c|}{$P$-values } & \multirow{3}{*}{\multicolumn{2}{|c|}{$\begin{array}{cc}\text { Compared } & \text { Difference } \\
\text { treatments } & \text { in } \\
& \text { means }\end{array}$}} & \multicolumn{4}{|c|}{$P$-values } \\
\hline & & \multirow[b]{2}{*}{ Unadjusted } & \multicolumn{3}{|c|}{ Adjusted } & & & \multirow[b]{2}{*}{ Unadjusted } & \multicolumn{3}{|c|}{ Adjusted } \\
\hline & & & $\begin{array}{l}\text { List } \\
\text { et al }\end{array}$ & Bonferroni & Holm & & & & $\begin{array}{l}\text { List } \\
\text { et al }\end{array}$ & Bonferroni & Holm \\
\hline T1 vs. T2 & 0.610 & 0.190 & 0.393 & 1 & 0.571 & T1 vs. T2 & 1.633 & 0.044 & 0.107 & 0.268 & 0.134 \\
\hline T1 vs. T3 & 0.383 & 0.393 & 0.608 & 1 & 0.787 & T1 vs. T3 & 0.740 & 0.335 & 0.335 & 1 & 0.335 \\
\hline T2 vs. T3 & 0.227 & 0.612 & 0.612 & 1 & 0.612 & T2 vs. T3 & 0.893 & 0.287 & 0.461 & 1 & 0.574 \\
\hline
\end{tabular}

farmers' support to the considered programme and commitment period tend to increase compared to the control treatment, these findings suggest that activating legacy concerns is not effective.

Let us now examine the effect of legacy (and non-legacy) priming on programme support and commitment period controlling for farmers' age, gender, education level, main activity (vegetables production, fruit-growing, viticulture, and cereals), production type (organic versus conventional), and, parents' profession (farmers or not). Estimation results are reported in Tables 8 (programme support) and 9 (commitment duration) together with the goodness-of-fit-measures. We also report marginal effects, computed as the difference between the probabilities estimated at the sample means when the dummy variable takes the values 1 and 0 , respectively. Marginal effects after an ordered probit

Table 8. Effect of priming on the level of programme support.

\begin{tabular}{|c|c|c|c|}
\hline \multirow{2}{*}{ Variables } & \multicolumn{2}{|c|}{ Ordered probit regression } & \multirow{2}{*}{$\begin{array}{l}\text { Linear regression } \\
\text { Coefficients and significance } \\
\text { (Standard errors) }\end{array}$} \\
\hline & $\begin{array}{l}\text { Coefficients and significance } \\
\text { (Standard errors) }\end{array}$ & $\begin{array}{l}\text { Marginal effect for } \\
\text { outcome } 10\end{array}$ & \\
\hline Intercept & & & $6.063^{* * *}(0.757)$ \\
\hline T3 (Legacy Motive) & $0.318^{*}(0.163)$ & $0.093^{*}$ & $0.758^{*}(0.459)$ \\
\hline T2 (Soil Quality) & $0.377^{* *}(0.171)$ & $0.113^{* *}$ & $0.922^{* *}(0.483)$ \\
\hline $\begin{array}{l}\text { Age }(=1 \text { if more than } 40 \text { years } \\
\text { old) }\end{array}$ & $0.151(0.174)$ & 0.044 & $0.332(0.487)$ \\
\hline Gender ( $=1$ if male) & $-0.109(0.163)$ & -0.031 & $-0.016(0.456)$ \\
\hline Education (=1 if high educated) & $0.172(0.140)$ & 0.048 & $0.440(0.396)$ \\
\hline Organic ( $=1$ if true) & $0.579^{* * *}(0.155)$ & $0.177^{* * *}$ & $1.617^{* * *}(0.433)$ \\
\hline Fruit growing (=1 if true) & $-0.042(0.264)$ & -0.011 & $-0.117(0.743)$ \\
\hline $\begin{array}{l}\text { Vegetables production ( }=1 \text { if } \\
\text { true) }\end{array}$ & $0.415(0.280)$ & 0.132 & $1.343 *(0.787)$ \\
\hline Viticulture (=1 if true) & $-0.287(0.198)$ & -0.083 & $-0.796(0.556)$ \\
\hline Cereals ( $=1$ if true) & $-0.095(0.375)$ & -0.026 & $-0.231(1.036)$ \\
\hline $\begin{array}{l}\text { Parents ( }=1 \text { if parents' participant } \\
\text { were farmers) }\end{array}$ & $-0.474^{* *}(0.150)$ & $-0.142^{* * *}$ & $-1.436^{* * *}(0.425)$ \\
\hline Number of observations ${ }^{(a)}$ & 254 & & 254 \\
\hline Pseudo $R^{2}$ & 0.0563 & & 0.2141 \\
\hline Log pseudo-likelihood & -501.39922 & & \\
\hline$F$ & & & $5.81^{* * *}$ \\
\hline Wilks' lambda & & & $0.6884^{* * *}$ \\
\hline Pillai's trace & & & $0.3230^{* * *}$ \\
\hline
\end{tabular}

$\left({ }^{*}\right),(* *)$ and $\left({ }^{* * *}\right)$ stand for significance at the 10,5 and $1 \%$ level, respectively; (a): The number of observations is 254 because some farmers did not answer all the questions used in the regression. 
Table 9. Effect of priming on the duration of commitment.

\begin{tabular}{lccc}
\hline Variables & \multicolumn{2}{c}{ Poisson regression } & $\begin{array}{c}\text { Linear regression } \\
\text { Coefficients and significance } \\
\text { (Standard errors) }\end{array}$ \\
\cline { 2 - 3 } & $\begin{array}{c}\text { Coefficients and significance } \\
\text { (Standard errors) }\end{array}$ & $\begin{array}{c}\text { Average marginal } \\
\text { effect }\end{array}$ & $\begin{array}{c}6.220^{* * *}(1.299) \\
1.522^{*}(0.788)\end{array}$ \\
Intercept & $0.198^{* *}(0.101)$ & $1.553^{*}$ & $2.432^{* * *}(0.829)$ \\
T3 (Legacy Motive) & $0.317^{* * *}(0.105)$ & $2.485^{* * *}$ & $1.934^{* *}(0.837)$ \\
T2 (Soil Quality) & $0.218^{* *}(0.090)$ & $1.708^{* *}$ & $0.856(0.783)$ \\
Age (=1 if more than 40 years old) & $0.110(0.101)$ & 0.865 & $0.182(0.680)$ \\
Gender (=1 if male) & $0.020(0.089)$ & 0.160 & $3.851^{* * *}(0.743)$ \\
Education (=1 if high educated) & $0.459^{* * *}(0.084)$ & $0.288(1.276)$ \\
Organic (=1 if true) & $0.076(0.163)$ & $0.596^{* * *}$ & $2.965^{* *}(1.350)$ \\
Fruit growing (=1 if true) & $0.307^{* *}(0.137)$ & $-0.639(0.954)$ \\
Vegetables production (=1 if true) & $-0.075(0.123)$ & -0.592 & $-1.180(1.777)$ \\
Viticulture (=1 if true) & $-0.176(0.229)$ & -1.380 & $-2.806^{* * *}(0.729)$ \\
Cereals (=1 if true) & $-0.339^{* * *}(0.086)$ & $-2.656^{* * *}$ & 254 \\
Parents (=1 if parents' participant & & & 0.2718 \\
$\quad$ were farmers) & 254 & & $7.97^{* * *}$ \\
Number of observations ${ }^{(a)}$ & 0.1339 & & $0.6884^{* * *}$ \\
Pseudo $R^{2}$ & -890.14644 & & $0.3230^{* * *}$ \\
Log pseudo-likelihood & & & \\
$F$ & & & \\
Wilks' lambda & & & \\
Pillai's trace & & & \\
\hline
\end{tabular}

$\left({ }^{*}\right),\left({ }^{* *}\right)$ and $\left({ }^{* * *}\right)$ stand for significance at the 10,5 and $1 \%$ level, respectively; (a): The number of observations is 254 because some farmers did not answer all the questions used in the regression.

estimation can be computed for each outcome of the dependent variable. However, for sake of exposition, we only present marginal effects for the highest level of programme support (see Appendix for all values). Regarding the Poisson regression, we report the average marginal effects (Cameron and Trivedi 1998). Moreover, we also provide the results of a multivariate linear regression in order to see how do they compare to the results of our models (Right column of Tables 8 and 9).

Tables 8 and 9 show that the legacy and non-legacy priming matters regarding both the programme support and duration of the commitment. We found that respondents in treatments $\mathrm{T} 2$ and T3 are likely to report significantly higher levels of support and commit in the examined environmental programme for a relatively longer period, compared to those assigned to the control treatment (T1, no prime). Nevertheless, given that both T2 and T3 are significant, we cannot conclude that the detected effect is only due to activation of legacy concerns. Regarding control variables, our estimation results show that organic farmers are more likely to report higher levels of support for the environmental programme (and commit for a longer period), compared to conventional ones. This variable has also the highest marginal effects. Organic farmers are 17.7 percentage points more likely to report that they fully support the programme compared to conventional ones. Moreover, being organic is associated with 3.596 additional years of commitment. However, multi-generation farmers (MG) are less likely to support (and commit for a longer period in) the programme, compared to first-generation farmers (FG). Marginal effects indicate that MG farmers are 14.2 percentage points less likely to choose the highest level of support compared to FG farmers. MG farmers are also associated with 2.656 less years of commitment, compared to FG producers.

One may, however, argue that the low pseudo R-square in both regressions may indicate that unobserved individual heterogeneity is still relatively important in the data. In addition, we cannot rule out the potential role of some omitted variables that might be associated with a given category of farmers, legacy effects and potential willingness to participate. We thus caution the reader to not over-interpret our findings. Notwithstanding these limitations, our results are consistent with those of Zaval, Markowitz, and Weber (2015) who found that the environmental concern and action were enhanced by the legacy motive priming, but their design did not use a non-legacy prime. Our results could be explained by the fact that the activation of a legacy motive could have enhanced among our participants their tendency to leave a positive legacy (Hunter and Rowles 2005; Newton 
Table 10. Effect of legacy and non-legacy priming on programme support and duration of commitment for MG versus FG farmers.

\begin{tabular}{|c|c|c|c|c|}
\hline \multirow[b]{2}{*}{ Variables } & \multicolumn{2}{|c|}{$\begin{array}{l}\text { Program support coefficients and } \\
\text { significance (Standard errors) }\end{array}$} & \multicolumn{2}{|c|}{$\begin{array}{c}\text { Duration of the commitment } \\
\text { Coefficients and significance (Standard } \\
\text { errors) }\end{array}$} \\
\hline & MG farmers & FG farmers & MG farmers & FG farmers \\
\hline Intercept & & & $1.648^{* * *}(0.203)$ & $1.607^{* * *}(0.203)$ \\
\hline T3 (Legacy Motive) & $0.256(0.203)$ & $0.504^{*}(0.303)$ & $0.245(0.150)$ & $0.242 *(0.130)$ \\
\hline T2 (Soil Quality) & $0.352 *(0.212)$ & $0.479(0.312)$ & $0.397^{* *}(0.156)$ & $0.270^{* *}(0.132)$ \\
\hline Age ( $=1$ if more than 40 years old) & $0.156(0.214)$ & $0.114(0.314)$ & $0.353^{* * *}(0.128)$ & $0.083(0.115)$ \\
\hline Gender ( $=1$ if male) & $-0.199(0.207)$ & $0.029(0.274)$ & $-0.077(0.150)$ & $0.274^{* *}(0.121)$ \\
\hline Education (=1 if high educated) & $0.147(0.173)$ & $0.252(0.249)$ & $0.085(0.127)$ & $-0.101(0.114)$ \\
\hline Organic ( $=1$ if true) & $0.513^{* *}(0.201)$ & $0.728^{* * *}(0.257)$ & $0.376^{* * *}(0.137)$ & $0.541^{* * *}(0.099)$ \\
\hline Fruit growing (=1 if true) & $-0.109(0.332)$ & $0.153(0.453)$ & $-0.019(0.229)$ & $0.146(0.212)$ \\
\hline Vegetables production ( $=1$ if true) & $0.315(0.411)$ & $0.577(0.399)$ & $0.131(0.237)$ & $0.556^{* * *}(0.159)$ \\
\hline Viticulture (=1 if true) & $-0.339(0.250)$ & $-0.233(0.333)$ & $-0.248(0.163)$ & $0.108(0.153)$ \\
\hline Cereals ( $=1$ if true) & $-0.143(0.430)$ & $-0.166(0.853)$ & $-0.388(0.270)$ & $0.078(0.343)$ \\
\hline Pseudo $\mathrm{R}^{2}$ & 0.0295 & 0.0573 & 0.0918 & 0.1409 \\
\hline Log pseudo-likelihood & -342.38576 & -156.52234 & -606.92029 & -265.86192 \\
\hline Number of observations & 167 & 87 & 167 & 87 \\
\hline
\end{tabular}

$(*),(* *)$ and $(* *)$ stand for significance at the 10,5 and $1 \%$ level, respectively.

et al. 2014) and to pass their own values through their organization. For example, Vess and Arndt (2008) argue that increasing mortality awareness reduces concern for the environment of participants whose self-esteem is not linked to environmental domain, but promotes environmental concern among participants who achieve self-esteem from environmental actions. Consequently, if farmers' values are not linked with environmental issues but with the desire, for example, to leave an autonomous and profitable farm, their environment concern would not be enhanced.

Last but not least, as mentioned in the introductory section, we also examined whether FG farmers exhibit or not different patterns compared to MG farmers (Table 10). Regarding the programme support, only the legacy prime is significant for FG farmers. For this sub-sample, the non-legacy prime (question about soil quality) is no longer significant. However, when considering the subsample of MG farmers, only T2 is significant. Regarding the duration of commitment to the examined environmental programme, the findings reported in Table 10 indicate that for the sub-sample of FG farmers, the results are quite similar to those obtained for the whole sample (T2 and T3 are both significant). However, for the sub-sample of MG farmers, only T2 (non-legacy prime) is significant. These findings are consistent with the argument of Bang, Zhou Koval, and Wade-Benzoni (2017) that first-generation farmers may be more likely to consider their legacy in terms of environmental achievements (see also the trend in Zaval, Markowitz, and Weber 2015, Supplemental material). Finally, similarly to the whole sample, our estimation shows that being organic increases the probability to report higher levels of support for the environmental programme and commitment for a relatively longer period, compared to conventional farmers.

Our study suggests that activating legacy concerns will not necessarily lead to similar environmental attitudes for first and multi-generation farmers. The good news is that activating legacy in a context of a recently founded family farm can initiate a virtuous process across future generations, where the business founder devotes more attention and efforts to environmental considerations. The not-so good news is that activating legacy among multi-generation farmers is less likely to produce the expected environmentally friendly reactions, given that the mental models of these farmers can be influenced by the desire to perpetuate the legacies of their predecessors. An interesting alternative to possibly redirect the legacy effect in a more socially desirable way can be to invite multi-generation farmers to go back to several generations where historical practices on their own farms were more in line with environmental considerations. For instance, Warren et al. (2016) indicate that in Scotland

SRC [short rotation coppice] is not the 'new' crop that it is often perceived as, but an ancient practice being reimagined to meet contemporary objectives. A cultural rediscovery of these historic linkages could aid the acceptability of energy crops in contemporary rural settings. 
To be cautious, this alternative must not be considered as a one-size-fits-all approach. Indeed, it can be very attractive and useful for some practices and not for others for which historical practices were misaligned with environmental considerations. Nevertheless, this proposition remains speculative and needs to be tested. Lastly, a sizeable research shows that multi-generation family businesses are not all created equal. A common perception of these family businesses as 'traditional, oldfashioned and stagnant' is stereotypical and outdated and could occult various entrepreneurial trajectories (Uhlaner et al. 2012). Applied to our issue, this insight may indicate that the legacy lever can generate various trajectories, even in the subsample of multi-generation farms, calling for further research.

\section{Conclusion}

Based on the behavioural literature about the legacy motive and its potential to increase environmental concern, we investigated the possibility to apply it to farmers in order to increase their intention to participate in an environmental programme. Using an experimental survey in the French Vaucluse area, we found that the legacy motive priming does not seem to affect the level of support for the implementation of ecological mitigation measures and contract duration. Nevertheless, we found a significant effect of activating the legacy motive for first-generation farmers who expressed higher intentions to support the considered conservation programme. Our findings suggest that activating legacy motives can affect differently various groups of farmers, according to their individual characteristics that need to be better identified. These results inform communication strategies on how legacy issues can be leveraged to mobilize some groups of farmers in order to increase support for some agro-environmental measures. Rather than adopting a one-size-fits-all approach, it makes sense to achieve pilot studies to better understand what legacy means for various subsamples and how subsamples of a given population react to legacy priming. Indeed, activating legacy concerns can constitute a low-cost nudge to encourage higher behavioural intentions regarding environmental measures, but not for all farmers. This activation can lead other farmers to consider more favourably other dimensions that can be unrelated or negatively related to the pursued environmental goals. Consequently, activating legacy concerns seems to require a tailored approach. Among potential candidates to distinguish these subsamples, it makes sense to consider farm size and annual revenue, previous commitments to green programmes but also the 'local' pressure to be green (e.g. farm located in a district with a strong green electorate). Moreover, given the relatively high effect of organic production in the regressions used in this paper, it would be also interesting to examine how this dimension interacts with legacy priming, possibly to promote further environmental efforts.

In a similar direction, it could be fruitful to explore how likely these results are to generalize to other countries with various agricultural systems. Given the predominance of grape-growing enterprises in our data set, a natural question related to other types of farms not examined in this manuscript that might be worthy of examination (e.g. predominance of dairy farms or non-perennial crops). An interesting issue is to examine whether our results still hold in times of economic downturn. For instance, rhe political discourse in France for economic recovery after the Covid-19 related downturn and the elections in June 2020 emphasized the urgent need to favour a green growth. Although it is speculative, such a 'brutal shock' could reinforce among some subsamples of the French population legacy concerns related to the environmental realm.

To go further, it could be also interesting to replicate this test with another control question in order to confirm its neutrality. Indeed, describing soil quality may have inadvertently put surveyed farmers in the perspective of an environmental prime. Even if this point is exact, it could indicate that environmental priming can be as effective as legacy priming among some subgroups of farmers, reinforcing the importance to better tailoring policy interventions. The soil quality priming appears to have the same impact as legacy priming. This suggests that (i) most of the effect is coming from priming irrespective of type or (ii) the soil quality priming is triggering a pro-environmental response similar to the legacy priming. Unfortunately, our data does not allow us to distinguish 
between these two possible sources. A natural way to go further would be to use another prime unrelated to the environment and see whether the results remain similar. If so, it would constitute an evidence in favour a pure priming effect. Another interesting question relates to the interaction of legacy concerns with the willingness to accept. It would be useful to better understand the supply curve of the proposed practice, but unfortunately, our design did not include variations in the compensation level offered.

Furthermore, we choose to conduct a non-incentive experiment, meaning that participants' answers did not have any financial implications. Although eminent scholars (e.g. Thaler 2015) have proved that such experiments provide reliable information, reproducing this test with a financial incentive could be promising. More precisely, given the conventional use of financial incentives in many developed countries to encourage farmers to adopt environmental measures, a full scale test or a field experiment (Harrison and List 2004) involving financial incentives and the use of legacy lever would deliver stronger and more reliable results that can inform policymakers. The results will not be limited to behavioural intentions but to real adoptions. We contend that the loss of control will be more than compensated by the increased external validity.

Our study constitutes a vibrant call to better examine how legacy concerns affect decisions of farmers and other family businesses and organizations, but also how these concerns can be harnessed to reach socially desirable goals. A preliminary step in this direction has been provided by Vandenbergh and Raimi (2015) who discuss innovative policies that leverage legacy concerns, e.g. by using a 'private legacy registry designed to record individuals' responses to climate change in ways that will not only be disclosed today, but will also be easily accessible for many generations'. Legacy 'nudges' can actually influence activities in various ways. It is possible that while different types of farmers respond differently to these types of prompts, they will not necessarily act differently in real life. Of course, we cannot directly assess whether these differential responses will actually result in different actions/decisions.

Our empirical instrument elicited stated preferences and it is expected that they are congruent with decisions that farmers would take if they face a similar situation in real life. Nevertheless, several studies have showed a discrepancy between the stated and revealed preferences, notably because of the hypothetical bias. Several methods have been proposed to design more reliable surveys such as cheap talk to caution participants about the likely mistakes in hypothetical scenarios (Ami et al. 2011), oath procedures to tell the truth (Jacquemet et al. 2013), or commitment procedures (Ami et al. 2014). Future hypothetical surveys about legacy effects can be improved by incorporating appropriate methods and then compare obtained results with real-world data.

Last but not least, legacy implies being remembered in the future, but by whom? We leave for further research the issue of better identifying the various groups who will remember the current decision-maker and the respective and combined effects of these groups (e.g. future farmers, family successors, citizens in the concerned area, local consumers of farm products (Borlu and Glenna 2020)) can have on legacy-related considerations. Its seems relatively intuitive that just evoking a given group rather than another in legacy activation can reinforce (or not) the likelihood of delivering socially desirable outcomes.

\section{Notes}

1. See for more details: https://agriculture.gouv.fr/maec-les-nouvelles-mesures-agro-environnementales-etclimatiques-de-la-pac.

2. http://www.trameverteetbleue.fr/presentation-tvb/qu-est-ce-que-trame-verte-bleue/definitions-trame-vertebleue?language $\% 3 \mathrm{Den}=\mathrm{fr}$.

\section{Acknowledgements}

The authors are grateful to Ezra Markowitz, Kaitlin Toner Raimi and two anonymous reviewers for their useful comments and suggestions. They also thank Katherine Farrow for editorial assistance. The authors also acknowledge 
financial support from the VITAL project (ERA-Net FACCE SURPLUS, European Commission grant 652615). This study is also a part of CompAg program (INRA ECOSERV-P10664 and ANR-17-CE32-0014).

\section{Disclosure statement}

No potential conflict of interest was reported by the author(s).

\section{Funding}

This work was supported by the VITAL project [ERA-Net FACCE SURPLUS, European Commission grant 652615]. This study is also a part of CompAg program [grant numbers INRA ECOSERV-P10664 and ANR-17-CE32-0014].

\section{ORCID}

Gilles Grolleau (D) http://orcid.org/0000-0003-2932-8870

Naoufel Mzoughi (D) http://orcid.org/0000-0002-8153-4615

\section{References}

Ami, D., F. Aprahamian, O. Chanel, R.-V. Joule, and S. Luchini. 2014. "Willingness to Pay of Committed Citizens: A Field Experiment." Ecological Economics 105: 31-39.

Ami, D., F. Aprahamian, O. Chanel, and S. Luchini. 2011. “A Test of Cheap Talk in Different Hypothetical Contexts: The Case of Air Pollution." Environmental and Resource Economics 50: 111-130.

Arrighi, J.-J., and S. Samyn. 2016. “Rapport Foncier INSEE Analyse PACA n040.” Accessed May 18, 2020. https://www. insee.fr/fr/statistiques/2501732\#documentation.

Bang, H. M., C. Zhou Koval, and K. A. Wade-Benzoni. 2017. "It's the Thought That Counts Over Time: The Interplay of Intent, Outcome, Stewardship, and Legacy Motivations in Intergenerational Reciprocity." Journal of Experimental Social Psychology 73: 197-210.

Barbera, F., I. Stamm, and R. L. DeWitt. 2018. "The Development of an Entrepreneurial Legacy: Exploring the Role of Anticipated Futures in Transgenerational Entrepreneurship.” Family Business Review 31: 352-378.

Borlu, Y., and L. Glenna. 2020. "Environmental Concern in a Capitalist Economy: Climate Change Perception Among U.S. Specialty-Crop Producers.” Organization and Environment. doi:10.1177/1086026619897545.

Calvet, C., P. Le Coent, C. Napoleone, and F. Quétier. 2019. "Challenges of Achieving Biodiversity Offset Outcomes Through Agrienvironmental Schemes: Evidence From an Empirical Study in Southern France." Ecological Economics 163: 117-130.

Camerer, C., and R. Hogarth. 1999. "The Effect of Financial Incentives in Experiments: A Review and Capital-Labor Production Framework.” Journal of Risk and Uncertainty 19: 7-42.

Cameron, A. C., and P. K. Trivedi. 1998. Regression Analysis of Count Data. Cambridge: Cambridge University Press.

Charness, G., U. Gneezy, and A. Imas. 2013. "Experimental Methods: Eliciting Risk Preferences.” Journal of Economic Behavior and Organization 87: 43-51.

Chrisman, J. J., J. H. Chua, and P. Sharma. 1998. "Important Attributes of Successors in Family Businesses: An Exploratory Study." Family Business Review 11: 19-34.

Chua, J. H., J. J. Chrisman, and P. Sharma. 1999. “Defining the Family Business by Behaviour.” Entrepreneurship Theory and Practice 23: 19-37.

DeFrancesco, E., P. Gatto, F. Runge, and S. Trestini. 2008. "Factors Affecting Farmers' Participation in AgriEnvironmental Measures: a Northern Italian Perspective.” Journal of Agricultural Economics 59: 114-131.

Dewey, C. 2017. “A Growing Number of Young Americans are Leaving Desk Jobs to Farm." The Washington Post, November, 23.

Fox, M., L. P. Tost, and K. A. Wade-Benzoni. 2010. “The Legacy Motive: A Catalyst for Sustainable Decision Making in Organizations.” Business Ethics Quarterly 20: 153-185.

Gaines, B. J., J. H. Kuklinski, and P. J. Quirk. 2007. “The Logic of the Survey Experiment Reexamined.” Political Analysis 15: 1-20.

Greene, W. 2003. Econometric Analysis. Upper Saddle River, NJ: Prentice-Hall.

Harrison, G. W., and J. A. List. 2004. “Field Experiments.” Journal of Economic Literature 42 (4): 1009-1055.

Harzing, A. 2000. "Cross-National Industrial Mail Surveys Why Do Response Rates Differ.” Industrial Marketing Management 29: 243-254.

Henriques, I., S. Kerekes, and P. Sadorsky. 2004. Environmental Management Systems and Practices: An International Perspective. Paris: OECD. 
Hertwig, R., and A. Ortmann. 2001. “Experimental Practices in Economics: A Challenge for Psychologists?” Behavioral and Brain Sciences 24: 383-451.

Hunter, E. G., and G. D. Rowles. 2005. “Leaving a Legacy: Toward a Typology.” Journal of Aging Studies 19: 327-347.

Inwood, S. 2013. "Social Forces and Cultural Factors Influencing Farm Transition." Choices 28: 1-5.

Jacquemet, N., R. V. Joule, S. Luchini, and J. F. Shogren. 2013. "Preference Elicitation Under Oath." Journal of Environmental Economics and Management 65: 110-132.

Jaskiewicz, P., J. G. Combs, and S. B. Rau. 2015. "Entrepreneurial Legacy: Toward a Theory of How Some Family Firms Nurture Transgenerational Entrepreneurship.” Journal of Business Venturing 30: 29-49.

Knowler, D., and B. Bradshaw. 2007. "Farmers' Adoption of Conservation Agriculture: A Review and Synthesis of Recent Research.” Food Policy 32 (1): 25-48.

Kruskal, W. H., and W. A. Wallis. 1952. "Use of Ranks in One-Criterion Variance Analysis." Journal of the American Statistical Association 47: 583-621.

Lastra-Bravo, X. B., C. Hubbard, G. Garrod, and A. Tolón-Becerra. 2015. "What Drives Farmers' Participation in EU Agri-Environmental Schemes? Results From a Qualitative Meta-Analysis.” Environmental Science and Policy 54: 19.

Lequin, S., G. Grolleau, and N. Mzoughi. 2019. "Harnessing the Power of Identity to Encourage Farmers to Protect the Environment." Environmental Science and Policy 93: 112-117.

List, J. A., A. M. Shaikh, and Y. Xu. 2019. "Multiple Hypotheses Testing in Experimental Economics." Experimental Economics. doi:10.1007/s10683-018-09597-5.

Liu, T., R. J. F. Bruins, and M. T. Heberling. 2018. "Factors Influencing Farmers' Adoption of Best Management Practices: A Review and Synthesis.” Sustainability 10: 432.

Mullinix, K. J., T. J. Leeper, J. N. Druckman, and J. Freese. 2015. “The Generalizability of Survey Experiments.” Journal of Experimental Political Science 2: 109-138.

Mzoughi, N. 2014. “Do Organic Farmers Feel Happier Than Conventional Ones? An Exploratory Analysis.” Ecological Economics 103: 38-43.

Newton, N. J., J. M. Herr, J. I. Pollack, and D. P. McAdams. 2014. "Selfless or Selfish? Generativity and Narcissism as Components of Legacy." Journal of Adult Development 21: 59-68.

Pintado, E., and M. Sánchez. 2017. "Researching the Entrepreneurial Behaviour of New and Existing Ventures in European Agriculture.” Small Business Economics 49: 421-444.

Read, D. 2005. “Monetary Incentives, What are They Good For?” Journal of Economic Methodology 12: $265-276$.

Rubinstein, A. 2001. “A Theorist's View of Experiments.” European Economic Review 45: 615-628.

Siebert, R., M. Toogood, and A. Knierim. 2006. "Factors Affecting European Farmers' Participation in Biodiversity Policies.” Sociologia Ruralis 46 (4): 318-340.

Thaler, R. 1987. "The Psychology of Choice and the Assumptions of Economics, Laboratory Experimentation in Economics: Six Points of View." https://doi.org/10.1017/S1478061500002656 (Accessed May 07, 2018).

Thaler, R. 2015. Misbehaving: The Making of Behavioral Economics. New York: W.W. Norton Company.

Uhlaner, L. M., F. W. Kellermanns, K. A. Eddleston, and F. Hoy. 2012. "The Entrepreneuring Family: A New Paradigm for Family Business Research.” Small Business Economics 38: 1-11.

Vandenbergh, M. P., and K. T. Raimi. 2015. “Climate Change: Leveraging Legacy.” Ecology Law Quaterly 42: 139-170.

Vercammen, J. 2011. “Agri-environmental Regulations, Policies, and Programs." Canadian Journal of Agricultural Economics 59: 1-18.

Vess, M., and J. Arndt. 2008. "The Nature of Death and the Death of Nature: The Impact of Mortality Salience on Environmental Concern." Journal of Research in Personality 42: 1376-1380.

Wade-Benzoni, K. A. 2016. "How to Think About Building Your Legacy." Harvard Business Review, December 15.

Wade-Benzoni, K. A., H. Sondak, and A. D. Galinsky. 2010. "Leaving a Legacy: Intergenerational Allocations of Benefits and Burdens." Business Ethics Quaterly 20: 7-34.

Wade-Benzoni, K. A., L. P. Tost, M. Hernandez, and R. P. Larrick. 2012. "It's Only a Matter of Time: Death, Legacies, and Intergenerational Decisions.” Psychological Science 23: 704-709.

Warren, C. R., R. Burton, O. Buchanan, and R. V. Birnie. 2016. "Limited Adoption of Short Rotation Coppice: The Role of Farmers' Sociocultural Identity in Influencing Practice.” Journal of Rural Studies 45: 175-183.

Zaval, L., E. M. Markowitz, and E. U. Weber. 2015. "How Will I be Remembered? Conserving the Environment for the Sake of One's Legacy.” Psychological Science 26: 231-236. 


\section{Appendix}

Marginal effects after the ordered probit regression for each outcome

\begin{tabular}{|c|c|c|c|c|c|c|c|c|c|c|}
\hline Variables & $\begin{array}{c}\text { Outcome } \\
1\end{array}$ & $\begin{array}{c}\text { Outcome } \\
2\end{array}$ & $\begin{array}{c}\text { Outcome } \\
3\end{array}$ & $\begin{array}{c}\text { Outcome } \\
4\end{array}$ & $\begin{array}{c}\text { Outcome } \\
5\end{array}$ & $\begin{array}{c}\text { Outcome } \\
6\end{array}$ & $\begin{array}{c}\text { Outcome } \\
7\end{array}$ & $\begin{array}{c}\text { Outcome } \\
8\end{array}$ & $\begin{array}{c}\text { Outcome } \\
9\end{array}$ & $\begin{array}{c}\text { Outcome } \\
10\end{array}$ \\
\hline T3 (legacy) & $-0.073^{* *}$ & -0.009 & $-0.011^{*}$ & -0.007 & $-0.019^{*}$ & -0.005 & 0.001 & $0.019^{*}$ & $0.010^{*}$ & $0.093^{*}$ \\
\hline $\begin{array}{l}\text { T2 (non- } \\
\text { legacy) }\end{array}$ & $-0.084^{* *}$ & $-0.011^{*}$ & $-0.013^{*}$ & $-0.008^{*}$ & $-0.023^{*}$ & -0.007 & 0.000 & $0.021^{* *}$ & $0.012^{* *}$ & $0.113^{* *}$ \\
\hline Age & -0.034 & -0.004 & -0.005 & -0.003 & -0.009 & -0.002 & 0.000 & 0.009 & 0.005 & 0.044 \\
\hline Gender & 0.025 & 0.003 & 0 & 0.002 & 0.006 & 0.001 & -0.000 & -0.006 & -0.003 & -0.031 \\
\hline Education & -0.04 & -0.005 & -0.00 & -0.00 & -0.009 & -0.002 & 0.002 & & 0.0 & 0.048 \\
\hline Organic & $-0.124^{* * *}$ & $-0.016^{* *}$ & $-0.020^{* *}$ & $-0.013^{* *}$ & $-0.037^{* * *}$ & $-0.012^{* *}$ & 0.002 & $0.029 * * *$ & $0.018^{* *}$ & $0.177^{* * *}$ \\
\hline Fruit growing & 0.010 & 0.001 & 0.001 & 0.000 & 0.002 & 0.000 & -0.001 & -0.002 & -0.001 & -0.011 \\
\hline $\begin{array}{l}\text { Vegetables } \\
\text { prod. }\end{array}$ & $-0.084^{*}$ & -0.012 & -0.015 & -0.009 & -0.028 & -0.010 & -0.000 & $0.018^{* *}$ & 0.012 & 0.132 \\
\hline Viticulture & 0.067 & 0.008 & 0.010 & & 0.016 & 0.004 & -0.002 & -0.018 & -0.010 & -0.083 \\
\hline Cereals & 0.023 & 0.002 & 0.003 & 0.002 & 0.004 & 0.000 & -0.001 & -0.006 & -0.003 & -0.026 \\
\hline Parents & $0.105^{* * *}$ & $0.013^{* *}$ & $0.016^{* *}$ & $0.010^{* *}$ & $0.029^{* *}$ & $0.008^{*}$ & -0.001 & $-0.026^{* * *}$ & $-0.015^{* *}$ & $-0.142^{* * *}$ \\
\hline
\end{tabular}

$\left({ }^{*}\right),\left({ }^{* *}\right)$ and $\left({ }^{* *}\right)$ stand for significance at the 10,5 and $1 \%$ level, respectively. 